\title{
ARAUCO DOMADO (1596) DE PEDRO DE OÑA Y LA IMITACIÓN ARTICULADA DE LA ENEIDA Y LA ARAUCANA
}

\author{
PEDRO DE ONA'S ARAUCO DOMADO (1596) \\ AND THE ARTICULATED IMITATION \\ OF THE AENEID AND LA ARAUCANA
}

\author{
SARissa Carneiro \\ Pontificia Universidad Católica de Chile \\ scarneir@uc.cl \\ orcid: 0000-0001-6012-4396
}

Resumen: Este artículo presenta un análisis del canto XIII de Arauco domado en cuanto imitación articulada del libro II de la Eneida de Virgilio y del canto XIII de La Araucana de Ercilla. Se plantea que el examen de este ejercicio de aemulatio permite observar no sólo la apropiación creativa que hace el poeta criollo de sus modelos antiguos y modernos, sino también importantes matices de sentido de la obra.

Palabras clave: poesía épica virreinal; imitatio en América; guerra de

Arauco; escritura criolla americana; pasiones.

Abstract: This article presents an analysis of Canto XIII of Arauco domado in terms of an articulated imitation of Book II of Virgil's Aeneid, and of Canto XIII of Ercilla's La Araucana. It is posited that by studying this exercise in aemulatio we are able to observe the creole poet's creative appropriation of models both ancient and modern, as well as appreciate significant nuances in the meaning of the poem.

Keywords: colonial poetry; imitatio in America; Arauco war; American creole writing; passions.

Recepción: 7 de enero de 2019; aceptación: 4 de octubre de 2019. 
Arauco domado del criollo Pedro de Oña (Angol, Chile, 1570Lima, ¿1643?) es el segundo poema épico sobre la prolongada guerra de Arauco*. Escrito y publicado en Lima en 1596, mantiene una relación de continuidad y distancia respecto de la obra que inaugura el género en América, La Araucana de Alonso de Ercilla, cuyas partes se imprimieron en Madrid en 1569, 1578 y $1589-1590$, respectivamente ${ }^{1}$.

La recepción crítica de Arauco domado extremó las diferencias con La Araucana, al punto de plantear una supuesta oposición de sentido entre ambos poemas. Como bien sintetizó Roberto Castillo Sandoval (1995), La Araucana se ha considerado desde muy temprano una piedra angular del mito fundacional de la historiografía y la literatura chilenas, mientras que "la obra de Oña ha sido criticada abierta o implícitamente por su esfuerzo de halagar al bando español representado en la figura de García Hurtado de Mendoza, a quien Ercilla colgara el baldón de «mozo capitán acelerado»". Pedro de Oña sería, según esa vertiente crítica, "el emblema de una mentalidad colonizada polarmente opuesta a la de un Ercilla supuestamente esclarecido y anticolonialista" (p. 234) ${ }^{2}$.

En los últimos años, valiosos estudios han contribuido a cuestionar tal simplificación. Castillo Sandoval no sólo proble-

* Este artículo se enmarca en el Proyecto de Investigación FONDECYT $\mathrm{n}^{\circ}$ 1180587, "La voz turbada: las pasiones en Arauco domado (1596) de Pedro de Oña. Modelos poéticos, códigos retóricos y visualidad” (2018-2020). Investigadora responsable: Sarissa Carneiro. Coinvestigadoras: Sandra Accatino (Universidad Alberto Hurtado) y Jéssica Castro (Universidad de Chile).

${ }^{1}$ La representación épica que hace Ercilla de la guerra de Arauco reina sin oponentes durante dos décadas: la Primera parte de "La Araucana" (Madrid, Pierres Cosin, 1569) cuenta con tres ediciones antes de la publicación de la Primera y Segunda parte (Madrid, Pierres Cosin, 1578), la cual tiene, a su vez, cinco ediciones antes de la publicación de la Tercera parte (Madrid, Pedro Madrigal, 1589). Citaré La Araucana siempre por la edición de Isaías Lerner, con la abreviación $L A$, seguida de la indicación de número de canto y octava. Lo mismo haré en las citas de Arauco domado ( $A D$, canto, octava), que remiten a la edición de 2014, llevada a cabo por Ornella Gianesin.

${ }^{2}$ Es el caso, por ejemplo, de Mario Rodríguez, quien señala: "Hay en La Araucana una evolución desde una imagen caballeresca heroica de la guerra, que reproduce el discurso oficial de la época, a otra concepción desilusionada que rompe las formas imperantes, aproximándola a la ideología lascasiana. Oña, a su vez, transforma el espacio abierto por Ercilla en un lugar arquetípico donde luchan las fuerzas de la luz cristiana contra las tinieblas del paganismo. El Arauco domado inscribe en las guerras de Chile la justificación ideológica de la Conquista" (1984, p. 124). 
matizó la mencionada lectura de La Araucana ${ }^{3}$, sino que también llamó la atención sobre la riqueza de Arauco domado como obra en que "se revelan con mayor profundidad las voces de todos los protagonistas de la pugna por el territorio de América" $(i d$.$) . Según este autor, en el poema de Oña hay una alian-$ za simbólica del criollo con el indígena en cuanto comparten una patria y un entorno vital; aunque esa alianza está marcada por un conflicto, ya que el araucano es visto simultáneamente como compatriota y como enemigo (p. 245).

Más recientemente, los estudios de José Antonio Mazzotti y de Mercedes Blanco han ahondado en esta línea ${ }^{4}$. Para Mazzotti (2008), la obra de Oña es representativa de una subjetividad criolla específica y temprana, caracterizada por "perspectivas y lealtades dobles" (p. 236). El crítico observa los cantos II, III y XIV-XVI de Arauco domado como fragmentos en que se advierte una perspectiva criolla paradójica. A partir de su análisis, Mazzotti señala que la crítica de Rodríguez (que define Arauco domado como una "imaginación colonizada" en un estudio que data de 1981) acierta en la posición política y pública de Pedro de Oña, pero "reduce a una identidad plana sus alcances ambiguos y por momentos plurisignificativos en el desentrañamiento de una agencia criolla" (p. 103).

Por su parte, Mercedes Blanco (2019) cuestiona la vertiente crítica que sostiene que los indígenas de Oña son "idólatras,

${ }^{3}$ Afirma Castillo SAndoval (p. 239): "Ercilla oscila entre su presentación del indio como ideal y su caracterización como ser capaz de una abyección e irracionalidad extremas; entre aquel encarnado en la figura de Caupolicán, fuerte, sereno y heroico, y la de Tucapel, violento, iracundo y enconado (aunque no menos valiente). Asimismo, su representación de Arauco alterna entre aquella de utópico locus amoenus digno de enmarcar grandes eventos históricos y la de territorio oscuro e inaccesible, escenario de bárbaras atrocidades y ceremonias paganas. En La Araucana, estas dos facetas no se encuentran desvinculadas sino, muy por el contrario, forman parte de una misma labor de codificación, la cual limita una lectura del poema como procedente de una «conciencia escindida», término que se aplica con mayor propiedad a los lectores criollos -antiguos y contemporáneos- de La Araucana".

${ }^{4}$ No incluyo aquí a Paul Firbas (2017), puesto que el crítico tiene respecto de Oña lo que podríamos llamar una postura intermedia: para Firbas, Oña desmonta la imagen de los indios como héroes dignos, tal como aparece en La Araucana, e intenta reducirlos "a una manifestación del mal, la idolatría y el inframundo" (p. 151). De todas maneras, Firbas concluye que "la fuerza de la poesía de Oña de algún modo traiciona su propio proyecto", pues fija imágenes que lo desbordan y minan (p. 153). 
salvajes, erotizados y afeminados" (p. 28) ${ }^{5}$. Su análisis del contenido amoroso de Arauco domado muestra de modo convincente la inadecuación de esas categorías aplicadas al poema de Oña. Para la autora, los afectos y conceptos amorosos, el coraje y la bravura jactanciosa de los personajes de Oña no son correlativos o complementarios con las borracheras, idolatrías o necromancia del canto segundo, sino que "van en direcciones opuestas y tienen efectos contrarios" (p. 32). Los "valientes y rendidos" amadores de Fresia, Gualeva y Quidora "son unos pocos araucanos escogidos por su rango y dignidad, a los que el poeta, de modo optimista, podría ver como interlocutores de una negociación que llevara a una paz estable" (p. 33).

El presente trabajo intenta profundizar en ese espacio de ambivalencias y matices del poema Arauco domado, desde el análisis de un elemento que ha sido menos atendido: su imitación transformadora de modelos antiguos y modernos. Se parte de la idea de que esta dimensión no oblitera los contextos y aportes locales, sino que, por el contrario, es insoslayable al momento de explorar las particularidades de un texto.

Como sintetizó Lina Bolzoni (2007), en la modernidad temprana "la producción de lo nuevo pasa a través de la imitación de lo antiguo" y "la individualidad del escritor puede expresarse sólo haciendo propio un discurso ajeno" (p. 12). El espacio individual se delinea como una zona de variación y combinación, un espacio entre los dos polos de una mecánica tomada de los componentes de los textos modélicos y de su reensamblaje en una reelaboración personal (Bolzoni 2012, p. 279).

La omisión de este aspecto lleva a desatender componentes fundamentales en la construcción de sentido de un texto. El arte de la imitación con variación opera en todos los elementos y niveles de un texto: la lengua, las metáforas, los artificios formales, como también "las imágenes, ese gran bagaje iconográfico que la literatura y el arte de los antiguos han transmitido" (Bolzoni 2007, p. 12). Por lo mismo, su análisis va mucho más allá de la simple identificación de tópicos que se reciclan ${ }^{6}$.

5 Afirma Blanco: "la citada serie de baldones, «idólatra, salvaje, erotizado y afeminado», dice más sobre la mentalidad puritana de parte de la crítica actual que sobre la de Pedro de Oña y sus contemporáneos" (p. 31).

${ }^{6}$ Estudios como el de María Dolores Castro y Almudena Zapata, "Tópicos de cuño virgiliano en el Arauco domado de Pedro de Oña" (2009), se limitan a ese aspecto, es decir, a la identificación de tópicos como el viaje por mar y la tormenta, el recuento de tropas, la fabricación de armas, etc., 
Autores como Pedro de Oña hicieron de la imitación un marcado gesto de apropiación y validación artística. Es posible afirmar que el criollo encaja en lo que Lina Bolzoni identificó como el tipo de lector más radical de lo antiguo, el que "nell'interpretazione va alla ricerca di se stesso e rimodella il testo altrui così da trasformarlo in uno specchio in cui proiettare, e insieme costruire la propria immagine" (2012, p. 55). Su apropiación del modelo virgiliano establece una relación de continuidad y diferencia: se confía a la memoria del lector la identificación de las alusiones al modelo, pero se juega a transgredir sus expectativas cuando se transforma e invierte la trama virgiliana, para hacerla propia. Ese juego con lo antiguo es, además, la base desde la cual Oña establece su relación intertextual con La Araucana de Ercilla.

\section{UN CASO DE IMITACIÓN ARTICULADA}

Como todo poema épico de la modernidad temprana, Arauco domado se compone en permanente diálogo con los modelos más prestigiosos del género: Homero, Virgilio, Lucano, entre los antiguos, Ariosto, Camões, Ercilla y Tasso, entre los modernos. A lo largo del poema, se pueden encontrar alusiones más o menos explícitas a diversas obras que constituyen una cadena textual a la que Pedro de Oña no sólo rinde tributo, sino que aspira a completar con su transformación y adaptación de la materia particular de la guerra de Arauco.

Sin embargo, junto con esta práctica imitativa corriente, tiene lugar en el canto XIII de Arauco domado una instancia de imitación articulada y programática ${ }^{7}$. Aquí el poeta

sin abordar el proceso de interpretación y variación del modelo virgiliano. El artículo analiza sólo los primeros doce cantos de Arauco domado, lo que llama la atención, dado que, como veremos, es el canto XIII el núcleo del juego imitativo con la Eneida. Jorge Fernández (2010-11), por lo demás, estudia la presencia de la mitología clásica en Arauco domado como demostración de una "imaginación colonizada" (término que adopta de Mario Rodríguez, sin cuestionar sus alcances).

7 En su comentario introductorio al canto XIII de Arauco domado, Gianesin (OÑA 2014 [1596]) refiere a la presencia de una "imitatio articolata" ("un processo di imitatio articolata: il poeta individua diversi luoghi di un libro specifico dell' Eneide, il secondo, e li rielabora, attivando, peraltro un meccanismo di ribaltamento rispetto alla fonte nel caso dell'episodio del serpente", pp. 373-374). Como veremos, el "vuelco" que emprende Oña 
no intenta disimular las referencias para hacer de la imitación una fuente de deleite exclusiva a los más doctos, sino que manifiestamente conduce al lector -incluso al más desavisado- a leer ese fragmento de la obra en relación con sus dos modelos fundamentales: el libro II de la Eneida y el canto XIII de La Araucana.

Es posible afirmar que aquí se produce lo que G.W. Pigman (1980, p. 27) observó en algunos autores del Renacimiento: se abandona el principio poético de la disimulación (en cuanto moderada ocultación de los modelos imitados con el fin de exhibir una personal "digestión" de los mismos o bien de reservar al lector el placer de reconocerlos) y se opta, en cambio, por llamar la atención y desafiar deliberadamente a que se establezcan comparaciones con otros textos ${ }^{8}$. En estos casos, como señala Pigman (p. 31), la relación entre texto y modelo pasa a ser, en sí misma, un elemento importante de la obra: a veces referida como aemulatio, este tipo de imitación busca asegurar que el lector observe las relaciones entre las obras, para advertir no sólo semejanzas, sino, sobre todo, diferencias y variaciones que

respecto de su fuente va más allá del episodio de la serpiente. De cualquier forma, tomo la categoría propuesta por Gianesin, que entiendo aquí como 'articulación de las distintas piezas o nudos poéticos que Oña recoge de sus modelos centrales (la Eneida y La Araucana) puestas en movimiento en una nueva trama'. El ejercicio es también programático, puesto que hay una declaración explícita que obedece al afán de destacar la relación imitativa, la transformación de las piezas antiguas y modernas, y la construcción de un nuevo sentido que refuerza una determinada poética y una visión de los acontecimientos. En el Apéndice que cierra este trabajo puede observarse una tabla sintética de la imitación articulada que Oña llevó a cabo en el canto XIII de su obra.

8 A partir de las reflexiones de distintos autores y poetas del Renacimiento sobre la imitación, Pigman (1980, p. 32) distingue tres modalidades básicas de ésta: seguir, imitar y emular, conceptos de fronteras relativamente fluidas pero que, en términos generales, apuntan a 1) una imitación no transformadora; 2) una imitación con cierto grado de transformación (en la que operan metáforas como asimilación, digestión, parecido entre padres e hijos, etc.); y 3) una imitación erística o fuertemente transformadora (aemulatio) que reflexiona sobre el modelo y aspira a superarlo teniendo en cuenta la distancia histórica entre el presente y el pasado. Al igual que Pigman, en este trabajo emplearé siempre el término genérico imitación, entendiendo que comprende no sólo una modalidad específica, sino todo el abanico de posibilidades imitativas: "in practice it is often difficult to distinguish precisely imitation from emulation or following. Consequently, I use imitation to designate both the larger class and one member of it" (p. 3). 
conducen, idealmente, a la superación del modelo, en la medida en que se lo actualiza y adapta al presente ${ }^{9}$.

En Arauco domado, esta intención de hacer visible el juego de la imitación se plasma en tres notas al margen que contienen referencias explícitas a los principales modelos del canto XIII. Estos fragmentos son:

Texto

Octava 52

* ¿Cuán otro le vi yo de aquel Lautaro que sólo su valor, si al cielo plugo, sacó nuestra cerviz del grave yugo en que estuviera agora el suelo caro! Aquel que siempre fue nuestro reparo y de cristianos áspero verdugo, aquel que en la batalla de Valdivia así nos encendió la sangre tibia.

Octava 64

Yo, visto ser aquel intento rudo, le dije todo en lágrimas bañado:

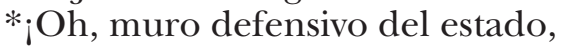
oh, tú, del español cuchillo agudo! ¿Quién mancillar así tu rostro pudo? ¿Quién ha tu fuerte cuerpo maltratado? ¿En qué lugar has hecho *tanta mora? ¿De dónde, cómo, a qué veniste agora?

\section{Octava 81}

Al yugo de un hispano sometiste el cuello de que siempre me colgaste.

9 Respecto de este punto, Pigman (p. 30) cita a Erasmo de Rotterdam: "For Erasmus the primary duty of the imitator is to be aware of the differences between his own day and antiquity, in particular to recognize the moral and stylistic revolution of Christianity, and to adapt the writings of the past to the conditions of the present. Historical decorum requires that the imitator found his style on the insight, «I see everything changed»". Esta doble actualización (moral y estilística o poética), entendida como un deber del imitador cristiano de lo antiguo, implica, en el caso de autores coloniales como Pedro de Oña, una tercera dimensión: la actualización o adaptación a un Nuevo Mundo, con todo lo que ello acarrea en términos morales, epistemológicos, políticos, etcétera.

${ }^{10}$ La anotación "frasis latina" apunta al calco de los versos virgilianos: "O lux Dardaniae, spes o fidissima Teucrum, / quae tantae tenuere morae?" (Eneida, 2, vv. 281-282). 
¿Así la prometida fe guardaste

y lo que aquella noche me dijiste?*

En vida solamente me seguiste,

* Lee el canto 13 de

"La Araucana", al fin. y en muerte, como sombra, me dejaste, que dura mientras luce el sol dorado, y acábase en habiendo algún ñublado ${ }^{11}$.

Puestas en momentos decisivos del canto, estas notas no sólo advierten al lector de las deudas poéticas de Oña, sino que además pretenden guiarlo hacia una determinada manera de leer el poema, una lectura atenta al juego de la imitación con variación, que observe tanto la "frasis latina" como la complejidad del entramado textual desde el cual Oña busca plasmar su propia escritura ${ }^{12}$.

Ya antes de la primera indicación al margen, el lector sin duda advertiría el juego propuesto por Oña, pues el canto, a más de presentar como sus dos nudos centrales la amenaza de la serpiente sufrida por Talguén (claro eco de la muerte de Laocoonte) y la aparición espectral de Lautaro (condensación de las figuras fantasmales de Héctor y Creúsa), sigue, para el relato en analepsis de Talguén a sus amigos, el modelo del que Eneas refiere a petición de Dido en el libro II de la Eneida.

Vale la pena sintetizar el contenido de este canto XIII con el fin de observar la diversidad de los procedimientos imitativos y los alcances de las transformaciones que realiza Pedro de Oña. Al final del canto XII, los amantes araucanos Tucapel y Gualeva se habían encontrado con su amigo Talguén. Éste, al igual que Tucapel, había abandonado la batalla en el fuerte de Penco y, tras vagar por el bosque, se había refugiado bajo un espino, en precarias condiciones físicas, a causa de la gran cantidad de heridas sufridas en combate. Al encontrarse, los amigos solicitan mutuamente el relato de lo ocurrido tras el enfrentamiento. La larga historia de Tucapel y Tegualda se resume en dos octavas por medio de un discurso indirecto (oct. 7: "Gualeva le contó lo sucedido..."; oct. 8: "Tras esto Tucapel también le cuenta..."); pero el relato de Talguén ocupa buena parte del

11 Aunque cito el texto fijado en la edición de Gianesin (OÑA 2014 [1596]), modernizo las grafías sin trascendencia fonemática.

${ }^{12}$ Las notas marginales de la primera edición de Arauco domado son de distintos tipos (aclaraciones etnográficas, históricas, traducción de términos indígenas, etc.). La que aparece en la octava 52 es la única, en toda la obra, que indica explícitamente un ejercicio de imitación. 
canto (octavas 26-94). En su sermocinatio, cede la voz, a su vez, al espectro de Lautaro, quien contará -también en analepsislos detalles de su muerte. El discurso de Talguén dura lo que jornada y camino hasta llegar a la rústica cabaña de los pastores donde los amigos buscan refugiarse del peligro del descampado. En la cabaña -sabrá el lector en las últimas octavas- se encuentra la amada de Talguén, Quidora. El final pastoril del canto incluye una tópica alabanza de la vida rústica, rebatida por Tucapel con una defensa de la guerra. La acción en Arauco se cierra aquí, pues todo lo demás (cantos XIV-XIX) referirá en prolepsis acciones posteriores que tendrán lugar durante el gobierno de García Hurtado de Mendoza como virrey del Perú.

De este modo, el canto XIII cumple una singular función de bisagra en el poema: el movimiento del canto (reforzado por la imagen de la caminata de los amigos hacia la choza de los pastores) va de lo épico a lo pastoril, movimiento que apunta también al tránsito general de la obra, desde una acción principal épica que alberga componentes amorosos y pastoriles (cantos I-XII) hasta un marco pastoril que contiene el sueño y visión profética de lo histórico-épico posterior (cantos XIVXIX). Como espacio para la visión, la humilde choza de Guemapu reemplaza la maravillosa cueva de Fitón ( $L A$, XXIII) que Ercilla describiera a partir del modelo de la hechicera Tesalia (Lucano, La Farsalia, VI y IX).

Este tránsito se relaciona con una tensión manifiesta que el poeta promueve respecto de su propia escritura. A diferencia de Ercilla -que se propuso en la primera parte de La Araucana restringir su materia poética a lo histórico-bélico, en oposición a Ariosto y a las innovaciones del romanzo italiano ("No las damas, amor, no gentilezas...”, I, 1)-, Pedro de Oña llega a afirmar que su verdadero estilo es el pastoril. Dirigiéndose a su mecenas y héroe de Arauco domado, dice:

Cuando mejor le sepa dar el corte, y si la Parca no me corta el hilo, yo cortaré, señor, con otro filo, tus venturosos lances en la corte: mas has de permitirme que los corte en traje pastoril, mi propio estilo; que en esto ni será él de corte sano, ni bastará tan poco el cortesano ( $A D$, III, 33). 
La promesa de Pedro de Oña de dar continuidad a la alabanza de García Hurtado de Mendoza en otro estilo no sólo apunta a la idea de escribir una segunda parte de Arauco doma$d o^{13}$, sino también a una serie de poco veladas quejas hacia su mecenas. Si en el prólogo y en el canto VIII, oct. 36, el joven poeta lamenta la premura con que ha tenido que escribir ${ }^{14}$, en la citada octava del canto III desliza la incomodidad que le produce el estilo épico; "has de permitirme que los corte en traje pastoril, mi propio estilo".

En este conflicto entre la natural inclinación hacia un estilo y la demanda del virrey mecenas, operaba también una tradición de escritura con la cual Oña debía estar familiarizado: aquella que, en las huellas de Virgilio, preceptuaba un camino desde la "flauta campesina" hacia las armas de Marte ${ }^{15}$. El criollo, que emprendía la escritura de Arauco domado antes de cumplir los veinticinco años, se veía constreñido por el molde épico exigido, temiendo no alcanzar la "soberana cumbre" tanto de su héroe como de su modelo inmediato (Ercilla). La vía pastoril, como primer paso de un proceso de formación poética, tenía, además, un importante componente moral que atribuía

13 Dice Oña en el "Prólogo al lector": "aunque en esta primera parte no quede Arauco domado, al menos dispónese (como se verá por el discurso) para que lo quede en la segunda" (p. 549). La promesa de segunda parte se reitera al final de la obra, en XIX, 113: "y nadie puede más de lo que puede; / mas, si el benigno cielo me concede / del todo que me falta alguna parte, / yo sacaré tras ésta la segunda, / con pie más lento y mano más fecunda".

${ }^{14}$ En el "Prólogo al lector", excusa las eventuales faltas de su poema con "la priesa tan grande cuan forzosa que en todo este discurso he llevado" (p. 549; énfasis mío). En VIII, 35, señala: "Es el discurso largo, el tiempo breve, / cortísimo el caudal del parte mía, / y danme tanta priesa cada día / que no me dejan ir como se debe". Y en la octava siguiente agrega: "En obra de tres meses que han corrido / he yo también corrido hasta este canto: / mirad si para haber corrido tanto / es mucho no ir el verso tan corrido; / mas yo con él quedara bien corrido, / si no corriera todo lo que canto / derecho a socorrerse de un mecenas / que bien hará correr las cojas venas”. Nótese la derivación con paronomasia de correr - corrido - socorrerse de un mecenas correr las venas, semejante a corte (de cortar) - corte (lugar) - cortesano - corte sano de III, 33. En ambos casos, el conceptismo agudo y el efecto lúdico de la figura poética permiten combinar encomio y queja.

15 Se trata de una carrera poética de estructura virgiliana, una progresión que va del género pastoril al épico. Colin Burrow (1997, p. 82) comenta que algunos autores, como Dante, ya mostraban independencia respecto de esa idea, pues sus églogas neolatinas son del período final de su vida. 
un significado alegórico a la vida de Virgilio y a la Eneida en particular, como progresión del alma de la infancia a la madurez ${ }^{16}$.

A la luz de estos antecedentes, el paso que tiene lugar en el canto XIII de lo épico a lo pastoril puede entenderse como una inversión de la habitual carrera virgiliana, pero también como reorientación hacia un camino que desde el comienzo se siente como propio. Esta inversión funciona, además, cual marco general para otra serie de inversiones de patrones virgilianos en Arauco domado. Observemos que, en la Eneida, el enfrentamiento entre griegos y troyanos está preludiado por la muerte de Laocoonte y la aparición de Héctor; la huida de Troya es posterior a todo ello, como culminación de la acción narrada por Eneas en el libro segundo. En Arauco domado, el modelo es imitado en orden inverso: la amenaza de la serpiente (eco de Laocoonte) y la aparición de Lautaro se dan después de la batalla de Penco y la huida de los araucanos.

Eneida 2

Laocoonte.

Fantasma de Héctor.

Enfrentamiento entre griegos y troyanos.

Huida de Eneas.

"Sombra de Creúsa".
Arauco domado

Canto VI

Enfrentamiento entre araucanos y españoles.

Huida de los araucanos del fuerte de Penco.

Canto XIII

Talguén como Laocoonte.

Fantasma de Lautaro.

Desde este marco general de inversiones, la imitación específica del libro II de la Eneida emplea otros procedimientos de gran efectividad, como la fusión, la amplificación y lo que se podría llamar la neutralización del efecto trágico. Comentaré estos recursos a partir del análisis de momentos esenciales del canto XIII de Arauco domado.

\section{TALguén Como LaOcoonte araUCANo}

En su extenso discurso directo, Talguén cuenta a sus amigos cómo, refugiado bajo un espino y agonizando con "mortífe-

16 Más detalles sobre esta interpretación de Virgilio en Burrow 1997. 
ras heridas" (XIII, 26), se le aparecen primero una serpiente y luego el fantasma de Lautaro. La aparición de la serpiente recordaba de inmediato la famosa muerte de Laocoonte y sus hijos, imagen que en el siglo Xvi se erigió como máximo exemplum doloris ${ }^{17}$.

No bien el tabernáculo pungente estuvo con mis miembros ocupado, cuando sentí salirme por un lado con silbos temerosos un serpiente: vile venir moviéndose la frente, cabeza, cuello y pecho levantado, girando con la cola por el heno y echando por los ojos su veneno.

A más andar llegándose venía, jugando de su lengua tan ligera, que no sé yo por cierto si lo era, mas ella de tres puntas parecía; yo, triste, que moverme no podía, ni sin dolor echar el huelgo fuera, por fuerza hube de estarme do me estaba, y con mi riesgo ver en qué paraba

$$
\text { ( } A D \text {, XIII, } 34 \text { y } 35) \text {. }
$$

Las resonancias intertextuales con Eneida 2 son claras. Recordemos el texto de Virgilio:

Ecce autem gemini a Tenedo tranquilla per alta (horresco referens) immensis orbibus angues incumbunt pelago pariterque ad litora tendunt; pectora quorum inter fluctus arrecta iubaeque sanguineae superant undas; par cetera pontum pone legit sinuatque inmensa uolumine terga. Fit sonitus spumante salo; iamque arua tenebant

17 Tal como señala SAlvatore Settis (1999), la escultura que representa a Laocoonte y a sus hijos, creada por Agesandro, Polidoro y Atenodor en el siglo I, fue celebrada y citada como insuperable ejemplo de expresión del dolor y del sufrimiento humano por artistas y escritores, desde el momento de su descubrimiento en Roma, en 1506. En los mismos años en que Oña escribía Arauco domado, poetas y teóricos italianos la convirtieron en uno de los centros de la discusión sobre la capacidad de representación de las artes figurativas, en abierta contraposición a las de la palabra. Para este tema, cf. Accatino (en prensa). 
ardentesque oculos suffecti sanguine et igni, sibila lambebant linguis uibrantibus ora

(Eneida 2, vv. 203-211; cursivas mías $)^{18}$.

El pecho erguido de las serpientes virgilianas se evoca en el verso de Oña "cabeza, cuello y pecho levantado"; los ardientes ojos, en "echando por los ojos su veneno"; las lenguas vibrátiles, los belfos silbadores del texto latino, en la "lengua ligera" y los "silbos temerosos" del poeta criollo, descriptio que remata en la octava 41 con la mención de la "vibradora lengua esquiva, / lanzando fuego y sangre por la saliva".

La proximidad con el texto virgiliano disponía el terreno para realizar, luego, interesantes transformaciones. La primera es de nuevo una inversión: el movimiento rápido de Laocoonte, que acude arma en mano a la defensa de sus hijos y lucha por soltarse de los nudos en que lo envuelven las serpientes, contrasta con la inmovilidad de Talguén, "yo, triste, que moverme no podía", "por fuerza hube de estarme do me estaba". El contraste se refuerza, después, en el plano de la retórica de las pasiones: el horror que provoca el ataque a Laocoonte y sus hijos ${ }^{19}$, horror que se reaviva en Eneas con tan sólo contarlo ("horresco referens"), se opone a la falta de temor de Talguén, que a él mismo sorprende:

Verdad es que jamás acá en mi pecho, después de aquel primer sobresalto, el pálido temor me hizo salto, aunque pudiera en otro haberle hecho; debiólo de causar, según sospecho, el verme ya de vida casi falto, y estar sin esperanza de tenella, porque esto quita el miedo de perdella (AD, XIII, 36).

En ese contexto se presenta la más radical de las inversiones en la imitatio articulada de Eneida 2: a pesar de su aspecto estremecedor, la serpiente que se acerca a Talguén no sólo no lo daña, sino que incluso le hace "halagos y caricias":

18 Cito siempre la edición de Cátedra del texto latino (2003).

19 Concluye la narración de la muerte de Laocoonte en Eneida 2, vv. 228-229: "Tum uero tremefacta nouus per pectora cunctis / insinuat pauor". 
...cual mansa bestia de buen tresno, reptando mansamente a mí se vino, humilde con la parte que es suprema y haciendo mil arillos de la extrema.

Llegóseme doméstico y tratable, mostrando con halagos y caricias haber librado todas sus delicias en deliciar mi cuerpo miserable; y deslizando el suyo deleznable, me estuvo allí pidiendo albricias de alguna buena nueva que me diese, como si para mí posible fuese.

Tal vez de largo a largo se tendía y el vario lomo liso me mostraba; tal vez en una Troya se tornaba; tal vez un solo círculo hacía; agora ya conmigo se medía; agora ya por medio atravesaba mi cuerpo sanguinoso, paseando con tacto cosquilloso, mole y blando.

Mas ya después haber lo dicho hecho, me circundó tres veces blandamente, y a la tercera vuelta fieramente enarboló otra vez cabeza y pecho; por donde vino, así volvió derecho, silbando y sacudiendo cresta y frente, y con su vibradora lengua esquiva, lanzando fuego y sangre por saliva

$$
\text { (AD, XIII, 38-41). }
$$

Algunos versos significativos buscan que no olvidemos el modelo antiguo: "me circundó tres veces", como las dos vueltas de los lomos escamosos en el cuerpo y cuello de Laocoonte; y al irse, "enarboló otra vez cabeza y pecho", como al principio, en ambos textos. Pero todo lo demás sorprende por su radical diferencia. La expectativa de ataque se disuelve en un curioso baile de connotaciones eróticas, con gran despliegue sensorial: la serpiente deleita a Talguén con caricias, paseando por su cuerpo sanguinoso, con tacto cosquilloso y blando; sorpren- 
de su vista con diversas formas: muestra el lomo liso, se hace un círculo y luego se desploma en acrobacias que otra vez contrastan con la inmovilidad del araucano.

Se produce aquí un fenómeno recurrente en Arauco doma$d o$ : la neutralización del carácter trágico de las tramas antiguas que reelabora el poeta criollo. Esto ya se había dado antes del canto XIII, en el encuentro de Tucapel y Gualeva con una leona, escrito a partir de reminiscencias de la historia de Píramo y Tisbe, pero también privado del desenlace fatal. El procedimiento se reitera en toda la imitación articulada de Eneida 2, como veremos.

Con desafiante variación, Pedro de Oña aglutinaba, en la serpiente de Talguén, las serpientes de Laocoonte, la tradición judeocristiana vinculada al Génesis, así como el dato preetnográfico americano. Si en la narración del ibunché el poeta criollo afirmaba su crédito en el conocimiento de "frasis, lengua y modo" de los indígenas del sur de Chile ( $A D$, II, 57), en la imitación de Laocoonte llamaba la atención del lector sobre su adaptación del mito antiguo a las creencias indígenas: "Nota que es buen agüero entre los indios ver una culebra", dice al margen, explicación que confiere sentido al giro radical del poema.

Tal inversión mantenía, no obstante, un núcleo común: la condición de presagio, funesto en el caso de Laocoonte, feliz en el caso de Talguén ${ }^{20}$. Esto contribuía al esperado efecto de admiración, pasión vinculada en los siglos XVI y XVII a la agudeza y al ingenio. La neutralización del efecto trágico subrayaba la desproporción de los contrarios, pero el dato etnográfico revelaba la permanencia en el mundo antártico del carácter vaticinador del prodigio. Se trata de un artificio muy cuidado: como diría años después Baltasar Gracián en Agudeza y arte de ingenio: "pondérase la discordancia, y luego pasa el ingenio a dar la sutil y adecuada solución" (2011 [1648], p. 479), "concordar los extremos en el desempeño que en la ponderación se discordaron fue siempre gran ventaja de esta sutileza" (p. 481).

Extrañeza y admiración, como efectos esperados en el lector, se dan primero en el personaje, en cuanto transmisor de estas pasiones:

${ }^{20}$ Recuérdese que también en Eneida 2 hay un prodigio con signo positivo: la llama inofensiva en los cabellos de Yulo. Inofensivo fuego, como la inofensiva culebra que acude a Talguén. 
Quedé con un prodigio tan extraño gastando el pensamiento en mil quimeras, y aunque era cada cual de cien maneras, se conformaban todas en mi daño; mas como yo dudaba el desengaño, viniéronme a nacer al fin esperas, haciendo ya mi cierto mal dudoso y a mí por esta causa temeroso.

De suerte que, en viniendo la esperanza, en ese mismo punto vino el miedo, mas hube de esperallos a pie quedo, que cada cual probase en mí su lanza; si aquello fue señal de* buenandanza pensar, amigos, menos yo no puedo de que el feliz agüero se ha cumplido, pues a los ojos vuestros he venido * Nota que es buen
agüero entre los
indios ver una
culebra. $(A D$, XIII, 42-43).

Talguén pasa del desengaño a la esperanza y luego al temor y, por fin, a la felicidad, modulación afectiva en la que se advierte otra apropiación del modelo virgiliano. Los variados afectos que padece el araucano recuerdan los sucesivos cambios anímicos de Eneas en la pluma de Virgilio. Como sintetizó R.G. Austin (1964), el Eneas virgiliano (a diferencia de otras versiones antiguas) es un hombre desconcertado: incitado por la visión de Héctor a abandonar Troya, desatiende el mensaje; luego, movido por una esperanza exaltada, es testigo de la muerte de sus compañeros y después del mismo rey. Si bien recuerda en ese momento a su propia familia, en el camino a casa vuelve a olvidarla con un impulso furioso de matar a Helena; su madre Venus tendrá que volver a advertirle que debe abandonar Troya, lo que por fin será reiterado por el espectro de Creúsa ${ }^{21}$.

En realidad, la identificación de Talguén con Eneas se había iniciado mucho antes, en plena batalla de Penco: allí, el araucano piensa en su amada Quidora -imitación del recuerdo que sobresalta a Eneas al presenciar el asesinato de Príamo ${ }^{22}$. En

${ }^{21}$ Para Austin (1964), el retrato de Eneas es uno de los aspectos más originales de Virgilio respecto de la tradición anterior: el poeta no quería que su personaje tuviera una estatura heroica desde el comienzo, sino que apareciera disciplinándose lentamente, a partir del doloroso proceso de fracaso (pp. xv-xvi).

22 "At me tum primum saeuus cricumstetit horror. / Obstipui; subiit cari genitoris imago, / ut regem aequaeuum crudeli uulnere uidi / uitam 
ambos casos, el recuerdo es una imago que surge frente al personaje. Dice Talguén: "me despidió de sí la palizada, / no por temer la imagen de la muerte, / sino porque el amor no menos fuerte / allí me presentó la de mi amada, / tras cuya vista angélica llevado / por fuerza me aparté del estacado" ( $A D$, XIII, 28). La identificación Talguén-Eneas se consolida en el próximo paso del relato: la aparición del fantasma de Lautaro ante Talguén, imitatio de la de Héctor y Creúsa ante Eneas.

\section{LA APARICIÓN ESPEGTRAL DE LAUTARO}

En la aparición espectral de Lautaro, la imitación de Eneida 2 añade a los procedimientos ya comentados otros dos, de efectos contrarios: la fusión y la amplificación. En cuanto parte del ejercicio imitativo, estos procedimientos aportan varietas y destacan las habilidades transformadoras del ingenio criollo.

Como en el caso anterior, las variaciones se dan sobre la base de un sólido terreno de concordancias con el modelo. A nivel estructural, el esquema virgiliano de la visión espectral de Héctor se mantiene intacto en la de Lautaro: 1) la aparición espectral se da en contexto nocturno; 2) el personaje se sorprende y conmueve por el aspecto de la figura fantasmal, tan distinta del héroe en su esplendor; 3) se hace una descriptio física del espectro; 4) hay una reacción afectiva del personaje ante la visión; 5) hondos gemidos del espectro (al aparecer y antes de hablar); 6) el fantasma entrega su mensaje (de advertencia, en el caso de Héctor; no así en el de Lautaro, quien más bien pide venganza a su interlocutor) ${ }^{23}$.

exhalantem; subiit deserta Creusa, / et direpta domus et parui casus Iuli. / Respicio et quae sit me circum copia lustro" (Eneida 2, vv. 559-564).

${ }_{23}$ Recuerdo al lector el pasaje de la Eneida: "Era la hora en que el sopor primero, / don divino, en los míseros mortales / con íntima dulzura se insinúa. / De pronto en sueños levantarse miro, / visión inconsolable, Héctor en llanto: / negro de sangre y polvo, hecho un destrozo / por el arrastre de la biga, hinchados / los taladrados pies, como aquel día... / (¡Ay de mí, cuál estaba! ¡Cuán distinto / del Héctor vencedor que orna sus hombros / con las armas de Aquiles, o que lanza / dardanias teas a las dorias naves!) / barba y cabello en sangre enmugrecidos, / cuerpo con mil recientes cicatrices, / de tanta herida ante los patrios muros... / Al verlo así y al desatarme en llanto / me pareció que estas dolientes voces le dirigía yo: «iLuz de dardania / firmísima esperanza de los Teucros, / ¿cómo tanto tardaste, Héctor ansiado? / ¿de dónde así nos vuelves? ¡Con qué agobio / tras tanta ruina y tantos duelos 
$\mathrm{Al}$ respetar lo nuclear de la inuentio y la dispositio del episodio virgiliano, la variación de Oña oscila entre la dinámica de amplificación y la condensación o fusión de elementos dispersos en Eneida 2.

Una amplificación notable es la descriptio del aspecto físico deteriorado del héroe. Pedro de Oña no sólo extiende la descripción a varias octavas, sino que exagera los rasgos espantosos del espectro. Si Héctor aparecía negro de sangre y polvo, hinchados los pies, con mil cicatrices, Lautaro se muestra como el "más horrendo y mísero trasunto" (oct. 55) ${ }^{24}$.

Asimismo, la dimensión afectiva del fragmento es amplificada por Oña. Si Eneas dice haber llorado al ver la figura de Héctor (en un brevísimo "Ultro flens...", Eneida 2, v. 270), la reacción pasional de Talguén ocupa varias octavas, con una variación significativa: el llanto de Eneas se transforma en miedo paralizador en el indígena araucano:
Así le vi y, en viéndole delante, un yelo temeroso al mismo punto cayó sobre mi cuerpo y alma junto ${ }^{25}$, con un sudor helado en mi semblante; que luego por los huesos adelante se difundió, dejándome difunto,

patrios, / te tornamos a ver! Tu faz serena / ¿qué causa indigna la enturbió? Tus llagas / ¿qué me quieren decir?». / Nada responde / ni en mis vanas preguntas se detiene, / mas con hondo gemido: «Hijo de diosa, / sálvate de estas llamas, / ¡huye! -dice-; ;ya el enemigo la ciudad ocupa, / y se hunde Troya desde su alta cumbre! / Por Príamo y la patria harto se ha hecho; / si defensa tuviesen, de mi diestra / se la debió esperar. A ti sus cultos / y sus Penates encomienda a Troya: / tómalos, y compartan la fortuna / que los Hados te den. Para tus dioses / busca el amparo de potentes muros / que tras luengas ansiosas travesías / verás un día levantarse». Dice, / y saca del sagrario por su mano / Vesta, sus cintas y el eterno fuego" (2003, p. 405).

24 "Vi su cabeza casi un casco mondo / con cuál y cuál por ella largo pelo; / sus ojos, que alegraban tierra y cielo, / sumidos en un triste abismo hondo; / vi por las cuencas de ellos en redondo / un cárdeno color, ya turbio velo; / vi del mortal y pálido cubierta / su faz desfigurada, triste y muerta. // Su boca, ya de lobo y más escura, / lanzaba espeso humo por aliento; / sudaba un engrosado humor sangriento / su laso cuerpo y lóbrega figura; / y por la fiera llaga y abertura, / que tanto apresuró su fin violento, / mostraba el corazón que fue tan bravo, / vertiendo ya no sangre sino tabo" ( $A D$, XIII, 56-57).

${ }_{25}$ Gianesin (OÑa 2014 [1596]) anota la deuda de esos versos con otro fragmento de la Eneida: "Mihi frigidus horror / membra quatit gelidusque coit formidine sanguis" (III, vv. 29-30). 
y con la sangre ya cuajada y fría, si alguna en su lugar quedado había.

Pegose al paladar mi lengua helada, cerrome la garganta un grueso ñudo, huyóseme el sentido, quedé mudo, con toda la cabeza enerizada; pero la negra sombra a mí llegada no sé qué pudo hacer, mas tanto pudo, que luego me sentí con pecho fuerte para poder hablalla de esta suerte

(AD, XIII, 58-59).

Esta transformación del llanto en miedo implicaba, además, una fusión. En las octavas citadas, Pedro de Oña imitaba otros versos del texto virgiliano, sobreimprimiendo en el miedo de Talguén el de Eneas ante la aparición fantasmal de su esposa Creúsa: "Quaerenti et tectis urbis sine fine ruenti / infelix simulacrum atque ipsius umbra Creusae / uisa mihi ante oculos et nota maior imago. / Obstipui, steteruntque comae et uox faucibus haesit" (Eneida 2, vv. 771-774). Por lo mismo, así como Creúsa calma la angustia de Eneas, Lautaro -al hablar con Talguénhace que éste se sienta "ya bueno" (oct. 61) ${ }^{26}$. Finalmente, la fusión imitativa remata con el eco inconfundible de los tres intentos fallidos de abrazar al espectro (Creúsa/ Lautaro):

Eneida 2

vv. 792-794

Ter conatus ibi collo dare brac-

[chia circum:

ter frustra comprensa manus [effugit imago,

par leuibus uentis uolucrique [simillima somno ${ }^{27}$.
Arauco domado, XIII

Octava 62

Tres veces alargué mi cuello y

[brazos

para ceñir el suyo macilento, mas tantas me dejó burlado el

${ }^{26}$ El espectro de Lautaro cura las heridas de Talguén (octavas 66-67). Este fragmento fue uno de los más cuestionados en el juicio contra Arauco domado conducido por el deán de la Catedral de Lima, en 1596. La polémica arroja luces no sólo sobre la recepción inicial del poema de Oña, sino también sobre las expectativas, presupuestos y formas de lectura de las élites criollas virreinales a fines del siglo Xvi. Para mayores detalles acerca de la importancia de este fragmento del canto XIII, véase CARNEIRo (en prensa).

${ }^{27}$ Este conocido fragmento de Eneida 2 había sido reelaborado antes por Dante, en Purgatorio II, vv. 79-81: "Oh ombre vane, fuor che nell'aspetto! / Tre volte dietro a lei le mani avvinsi, / e tante mi tornai con esse al petto". 
y di a mi pecho inútiles abra-

[zos;

con que estuviera haciéndome

[pedazos,

a no cortar Lautaro el vano in-

[tento,

diciéndome: "No tienes que

[cansarte,

que en eso tú ni yo seremos

[parte".

Esta fusión (contaminatio), como parte del ejercicio de emulación, se vuelve compleja en la medida en que este paso del texto virgiliano remite, a su vez, a la Ilíada de Homero. En el canto XXIII, Aquiles busca abrazar el espectro de Patroclo, intento vano del héroe griego: "ponte de mí más cerca; abracémonos ambos, aunque por poco tiempo, y consigamos hartazgo y consuelo mediante nuestro lúgubre lamento. Así le habló en voz clara, y tendióle sus manos, pero no consiguió asirle; pues su alma, como el humo, tierra abajo marchóse entre chillidos" (2011, p. 962). La referencia al modelo homérico se hace evidente en Arauco domado cuando Lautaro pide venganza por su muerte para no seguir desterrado de los Campos Elíseos, clara alusión a la solicitud de Patroclo a Aquiles:

Iliada, XXIII

Arauco domado, XIII

vv. $70-75$

Entiérrame cuanto antes, pues Octava 84

que quiero pasar las puertas de Ya te mostré quién es el homiHades, y las ánimas lejos me rechazan, que los espectros son agora es bien mostrarte lo que de los difuntos y con ellas mezclarme allende el río hasta el venganza de él te pido por enmomento no me lo permiten; tero, antes bien, ando errante vana- si basta que Lautaro te la pida; mente alrededor del Hades, sola venganza puede darme vida, morada de anchas puertas. porque sin ella infausta muerte [muero,

Y por Torquato Tasso, en Gerusalemme liberata, XIV, 6: "Gli stendea poi con dolce amico affetto / tres fíate le braccia al collo intorno, / e tre fíate invan cinta l'imago / fuggia, qual leve sogno od aer vago", entre otros. Pero, como hemos visto, la imitación de Oña apunta directamente a Virgilio. 
pues solo por estar aún no ven-

[gado,

estoy de los Elisios desterrado.

De este modo, Pedro de Oña condensa en Lautaro las figuras de Héctor, Creúsa y Patroclo, lo que hace de su emulación un complejo juego de espejos capaz de reflejar, en nueva imagen, una larga y prestigiosa tradición. Este efecto caleidoscópico aplicado a Lautaro culmina estableciendo un diálogo con el modelo más cercano de Pedro de Oña, Ercilla. La variación respecto del héroe de La Araucana aporta un nuevo giro al personaje.

\section{"El CUELlo DE QUe SIEMPRE ME COlGASTE": CONTINUIDAD Y DISTANCIA CON LA ARAUCANA}

En un hábil ejercicio imitativo, Pedro de Oña une los hilos de las tramas antiguas y modernas cuando liga el cuello de Lautaro, que Talguén intenta abrazar (como Eneas a Creúsa y Aquiles a Patroclo), a los cuellos de Lautaro y Guacolda en su última noche de amor, tal como se narra en La Araucana, canto XIII. Nuevamente, Oña evita que su juego pase desapercibido: "Lee el canto 13 de La Araucana, al fin" reza al margen de "Al yugo de un hispano sometiste / el cuello de que siempre me colgaste. / ¿Así la prometida fe guardaste / y lo que aquella noche me dijiste?" ( $A D$, XIII, 81$)$.

Aquella noche, en La Araucana, XIII, Lautaro dormía con "la bella Guacolda enamorada", cuando de pronto despierta "congojoso" por haber soñado que un soberbio español lo oprimía. Guacolda queda turbada, pues también ha tenido un sueño funesto. Lautaro desconfía de todo presagio negativo, incitado por la fuerza del amor: "si vos queréis, señora, que yo viva, / ¿quién a darme la muerte es poderoso?” ( $L A$, XIII, 49). En ese momento, Ercilla une la imagen del cuello de los amantes abrazados a la del cuello en cuanto "yugo araucano sometido", superposición que aprovechará después Oña: "El hijo de Pillán con lazo estrecho / los brazos por el cuello le ceñía” ( $L A$, XIII, 48), y la amada, a su vez, "del cuello de Lautaro se colgaba" (LA, XIII, 52), cuando éste recuerda que gracias a él se ha restaurado la reputación de su pueblo, que antes había sometido "el soberbio cuello no domado" (LA, XIII, 50). 
De este modo, el cuello se transforma en una imago agens, es decir una imagen que materializa y hace visible una serie de conexiones de conceptos abstractos encadenados en la tradición literaria y artística, disponible para nuevas asociaciones ${ }^{28}$. En este caso, se entronca el sometimiento de los "bárbaros" araucanos a la sumisión amorosa, especialmente femenina, a partir de la difundida imagen del yugo matrimonial.

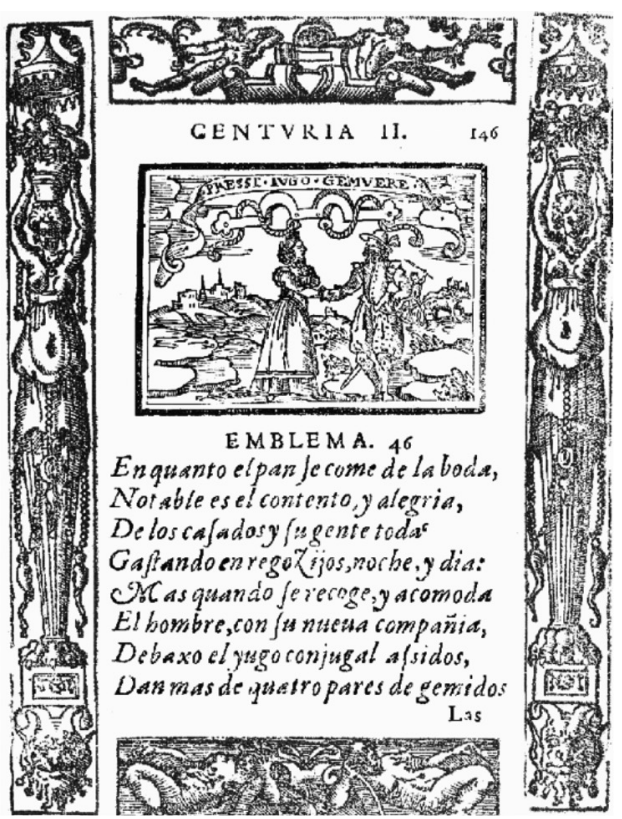

Fig. 1. El yugo del matrimonio en "Emblemas morales de don Sebastián de Covarrubias Horozco”, Luis Sánchez, Madrid, 1610.

El pasaje explicita varias connotaciones de la relación entre La Araucana y Arauco domado. Se establece un vínculo de continuidad, pero a la vez se busca llamar la atención del lector hacia la naturaleza particular de ese vínculo. La elección del

${ }^{28}$ Las imagines agentes sirven para la fijación de elementos del discurso según el arte de la memoria. Lina Bolzoni (2012) describe su poder de la siguiente manera: "L'arte della memoria insegnava infatti a collocare nei loci delle imagines agentes, delle immagini cioè che fossero capaci sia di condensare in sé, attraverso una catena di associazioni, i ricordi che vogliamo loro affidare, sia di restituirceli al momento del bisogno. L'immagine esemplare può dunque trasformarsi in imago agens, proprio perché condensa in sé il passato e lo fa rivivere nel presente e nel futuro attraverso una catena di associazioni che è molto forte" (p. 341). 
fragmento ercillano no es fortuita: se trata del primer momento en que Ercilla contradice su declaración inicial de cantar sólo a la guerra y no a los amores. Así pues, Pedro de Oña hace mucho más que remitir a una escena creada por su antecesor, al apuntar que de su modelo inmediato rescata y exacerba justamente aquello que allí era negación de un proyecto original plenamente bélico. Con ello, Oña refuerza y defiende su propia decisión de dar a las tramas afectivas un espacio central en su poema, lo que matizará, a su vez, el proyecto explícito de encomiar a García Hurtado de Mendoza, supuesto punto de distancia entre ambos poemas.

Asimismo, el fragmento comentado también subraya el tipo de relación que cada uno (Oña y Ercilla) entabla con Virgilio. En la figura de Guacolda se muestran las principales diferencias en lo que a ese punto se refiere. Si en La Araucana XIII, Guacolda promete suicidarse en caso de perder a Lautaro, en Arauco domado se encuentra sometida al "yugo hispano". Indica el autor al margen: "Nota que en este tiempo se había ya Guacolda casado con un español" ( $A D$, XIII, 80). El texto explica la situación echando mano del difundido topos de la mujer voluble: "¿para qué Guacolda, te condeno / si acudes a tu sexo femenino?", ( $A D$, XIII, 83); pero también aduce otra razón, menos tópica y más histórica: "en viéndome acabar la vida breve, / deseosa de hacer la tuya larga / buscaste nuevo amor y nueva carga", dice Lautaro ( $A D$, XIII, 80).

En La Araucana no había espacio para esa clase de acomodaciones coloniales: todas las heroínas indígenas respondían al mismo arquetipo de inquebrantable fidelidad, ideal que Ercilla proyectó también sobre el mundo antiguo, en concreto sobre la imagen de Dido, según él injustamente infamada por Virgilio (LA, XXI, 3). De hecho, en los cantos XXXII y XXXIII, Ercilla recurre a una tradición historiográfica previrgiliana para narrar la historia de la reina casta y comprometida con su pueblo, que se quita la vida para proteger Cartago y conservar la fidelidad a su esposo muerto ${ }^{29}$. En ese contexto, la transforma-

29 Para esta defensa de Dido en La Araucana, cf. GALPerin 2009. Para la defensa de Dido en la literatura española en general, cf. Lidd DE MALkiel 1974. En cuanto al rechazo de Virgilio por parte de Ercilla, la crítica ha formulado distintas opiniones. Según David Quint (1993), la defensa de Dido es una estancia explícitamente antivirgiliana que refuerza el vínculo de La Araucana con La Farsalia de Lucano, modelo de épica de los conquistados. Sin embargo, para Craig KAllendorf (2007), así como para RAúl 
ción de Guacolda de mujer fiel en nuevamente enamorada (iy de un español, extranjero como Eneas lo era para Dido!) es un nuevo tributo de Oña a Virgilio y un rescate de esa dimensión profundamente humana de sus personajes.

En efecto, la deuda más importante de Pedro de Oña con Virgilio radica en el relieve concedido a las pasiones. Ya en Virgilio ese componente se vinculaba a la imitación. Como demostró Gian Biagio Conte (2007, pp. 29-30), en la relación imitativa de Virgilio con Homero, la mayor cercanía textual contenía, a la vez, la mayor distancia: el modelo antiguo, impersonal, objetivo, compuesto de cosas (Homero), se hacía en Virgilio un texto nuevo infundido de una gran intensificación afectiva y patética. La voz narrativa de la Eneida se saturaba con la subjetividad de los personajes. Esto da lugar a lo que Conte (p. 23) llamó la "paradoja virgiliana": la Eneida pretende reflejar la ideología nacionalista de la épica romana en cuanto panegírico de Augusto, pero, al mostrar una extraordinaria empatía con los afectos de los personajes, alberga numerosos puntos de vista, algunos de ellos opuestos al relato imperial.

Algo semejante ocurre en Arauco domado. De la mano de Virgilio, Oña hace del páthos la médula de su ejercicio poético y crea una trama afectiva que debilita el proyecto explícito de alabar a su mecenas, al conceder a los personajes araucanos una elevación que remite a esa dimensión profundamente humana y pasional de los personajes virgilianos. En otros términos, el poema cumple el intento de dar voz a lo que Ercilla "de propósito" dejó callado (vale decir, "gloria y méritos" de García Hurtado de Mendoza, $A D$, I, 19), pero la intensa focalización afectiva en los personajes araucanos debilita la fuerza poética de la imagen del gobernador.

En la pluma de Oña, García Hurtado de Mendoza aparece como un cortesano virtuoso que domina tan perfectamente sus pasiones que se acerca a la apatía de los estoicos. Su retrato se forja a partir de concepciones morales y políticas católicas que aconsejan disimular, controlar y modelar afectos y pasiones violentas que, en cuanto negación de lo racional, introducen una suerte de fractura en el sujeto ${ }^{30}$. Pero ese

Marrero-Fente (2007), La Araucana presenta varios nexos con la Eneida, especialmente la utilización de distintas voces que subrayan las dificultades del proyecto imperial.

30 Para este asunto, véase Magli 1995. 
ideal político representado por el mecenas convive en la obra con un ideal poético que ve en las pasiones exaltadas una fuente de elocuencia ${ }^{31}$.

La tensión para responder a ambos ideales se hace visible en la imitación de Virgilio. Es cierto que García Hurtado de Mendoza aparece en Arauco domado como un nuevo Eneas que viaja a Chile superando tormentas y naufragios, que actúa con fuerza pero también con clemencia, y que lidera en el plano terrenal un combate de características trascendentales ${ }^{32}$. Sin embargo, la intención de duplicar el modelo heroico tiene como resultado una imagen fría y tópica. Sirva de ejemplo la referencia al escudo forjado por Vulcano para García Hurtado de Mendoza, imitatio del famoso fragmento de la fabricación de armas para Eneas: lo que en Virgilio es fragmento extenso y significativo, en Oña es brevísima mención que apenas cumple las expectativas de un panegírico ${ }^{33}$.

Por el contrario, como vimos en el análisis del canto XIII, cuando Pedro de Oña elabora personajes araucanos como Talguén, lo hace no sólo en estrecha cercanía con la figura de Eneas, sino con gran intensificación de la dimensión afectiva, fundamental en la poética virgiliana. Esto es aún más revelador

31 Para ilustrar esa concepción, sirva el siguiente fragmento de la Filosofía antigua poética (1596) de López Pinciano: "Los afectos y pasiones ayudan al furor natural poético" (anotación al margen); cuerpo del texto: "Del amoroso apetito que añada furor al poético es tan cierto que algunos hicieron a Cupido el inventor de la poética... La ira dice Horacio que armó a Archiloco de yambos. La indignación dice Juvenal que le hizo hacer versos. La codicia y el interés dice Persio que hace a los cuervos y picazas poetizar. El odio hizo a Salaya hacer las diras y maldiciones; y en suma, todo afecto, cuando es mucho, engendra furor, y añade al poético gran parte. Yo, a lo menos, conocí a un hombre que decía de sí que, cuando estaba enojado, Demóstenes le podía servir el aguamanos y Cicerón el paño, y que de Quintiliano no hacía caso, porque era un rateruelo" (Epístola III, f. 120).

${ }^{32}$ Remito al trabajo de Castro y Zapata 2009 para las coincidencias entre el gobernador de Chile y Eneas.

33 La mención se reduce a una octava: "Mostraba sobre el campo del escudo / a la fortuna lúbrica rendida, / y a la Ocasión por el copete asida / con poderosa mano en ciego ñudo; / esto es lo que forjar Vulcano pudo / contra la voluntad de su querida, / do el arte deja, yéndose de vuelo, / a la naturaleza por el suelo" ( $A D$, IX, 51). En atención a la imagen de un García Hurtado de Mendoza que controla sus pasiones y rechaza por completo el amor, el escudo del gobernador es fabricado por Vulcano sin autorización de Venus. La imagen forjada es de gran difusión en la época (Ocasión tomada por el copete y Fortuna rendida), con los célebres antecedentes de El Príncipe de Maquiavelo y Emblematum liber de Alciato. 
cuando la voz poética establece alianzas empáticas con los personajes indígenas, como ocurre en muchas octavas conclusivas de los cantos. Ese ingrediente, junto a las diversas focalizaciones del texto, colaboran a forjar ese carácter ambivalente que la crítica reciente ha visto en Arauco domado de Pedro de Oña.

\section{Conclusiones}

Hemos propuesto un análisis del canto XIII de Arauco domado, partiendo de la idea de que la meticulosa aemulatio que presenta del libro II de la Eneida y del canto XIII de La Araucana constituye un elemento fundamental no solamente para observar la apropiación creativa lograda por el poeta criollo, sino también para ampliar el examen de la plurisignificación de su obra (cf. infra "Apéndice").

Esta última participa de la tendencia general de la épica en cuanto género que permitió, desde antiguo, lecturas y sentidos diversos. Tal como indicó Paul Firbas (2017), los poemas épicos, si bien fueron sofisticadas maquinarias textuales que buscaron asegurar jerarquías y confirmar genealogías desde una alianza implícita con el poder, también constituyeron verdaderos laboratorios poéticos y narrativos que, en contexto americano (es decir, desde una posición desplazada), enfrentaron urgencias y realidades distintas, y dieron lugar a "usos nuevos de las viejas tradiciones" (p. 139).

En la referida multiplicidad de sentidos, la imitación de un texto clave de la tradición épica como la Eneida de Virgilio fue elemento no menor. El poema latino aportaba un modelo tanto para la afirmación del poder como para la advertencia de los costos y sufrimientos asociados al afán imperial. Por un lado, como advirtió Christopher Stray, la utilización de la Enei$d a$ durante la primera modernidad buscó mantener la solidaridad entre los grupos sociales de élite y la exclusión de los que no pertenecían a ellos (apud Kallendorf 2007, p. 6). En América, desde la idea de una translatio imperii, se trazaron comprometedoras genealogías entre la conquista del Nuevo Mundo y un pasado europeo que se remontaba al paso de Eneas desde Troya hasta Roma.

Sin embargo, al mismo tiempo, como observó Kallendorf, el texto virgiliano tuvo un uso distinto y funcionó como especie de "filtro" para reflexionar a propósito de la marginaliza- 
ción y la colonización ${ }^{34}$. Al estudiar la presencia de la Eneida en La Araucana de Ercilla, Kallendorf destacó esa doble faceta del uso del poema virgiliano; por un lado, es funcional al discurso del imperio (por ejemplo, la destrucción de Concepción sigue de cerca el saco de Troya, los araucanos son muchas veces representados como los enemigos de Eneas y pelean con furor incontrolable como Turno, se elogia a Felipe II como lo hace la Eneida con el emperador Augusto, etc.); pero, por otro, en diversos momentos, identifica a los araucanos con los troyanos, critica la malicia, la avaricia y otros vicios de los españoles, $y$, principalmente, invoca la necesidad de controlar las pasiones de ambos bandos, en un sentido semejante a la búsqueda de pietas en la Eneida (p. 91).

Escrito en la estela de La Araucana, y en una relación contradictoria de cercanía y distancia respecto de ella, Arauco domado buscó hacer aún más explícita su apropiación del modelo virgiliano mediante la imitación específica de un libro, el segundo de la Eneida, uno de los fragmentos más célebres del poema latino. Recuérdese, sólo a modo de ejemplo, lo que sobre dicho libro dijera san Agustín en sus Confesiones: en contraste con el disgusto que le producía el estudio de las matemáticas, "era para mí espectáculo dulcísimo la narración del caballo de madera lleno de gente armada, y el incendio de Troya, y la sombra de Creúsa" 35 .

Estudiado e imitado intensamente a través de los siglos, el libro segundo de la Eneida ofrecía un modelo fundamental no sólo para representar la destrucción (el saqueo, el incendio, etc.), sino también para evocar un origen que, partiendo de las ruinas, conducía a un viaje de búsqueda de destino y nuevo comienzo. Además, como ha observado Austin (1964, p. xi), Vir-

34 "I shall work to recover this other Virgil, who served in turn as a filter through which a series of highly original thinkers could construct a series of meditations on marginalization, colonization, and revolution", afirma KALLENDORF (2007, p. 14). Esta perspectiva se enmarca en las nuevas lecturas del mismo texto virgiliano, es decir, en la idea de que hay dos Eneidas, una "optimista", "focused on the celebration of empire and the values that made it great", y otra "pesimista", "in which the imperial project is probed, questioned, and occasionally subverted through the intermittent foregrounding of the voices of the colonized Other" (p. 78).

35 "Iam vero unum et unum duo, duo et duo quattuor, odiosa cantio mihi erat, et dulcissimum spectaculum vanitatis, equus ligneus plenus armatis, et Troiae incendium, atque ipsius umbra Creusae" (I, 22; véase la ed. de J.J. O’Donnell de 1992, p. 11). 
gilio tradujo tales estragos sobre todo en términos de relaciones humanas $^{36}$ : el libro segundo de la Eneida mostraba las últimas horas de Troya desde la mente de militares y civiles en tiempos de guerra, las tragedias personales que acarreaba, la desolación de una ciudad cuyas piedras eran conocidas y amadas por sus habitantes, la muerte de ancianos en sus propias casas...

Trasladado y adaptado al conflicto entre araucanos y españoles hacia mediados del siglo XvI, el célebre libro de la Eneida brindaba a esos hechos una dimensión de catástrofe y devastación innegables. A pesar de que la obra identificaba en varios momentos a García Hurtado de Mendoza con Eneas, en este canto la aemulatio transfería el universo virgiliano plenamente a los araucanos. La dura resistencia española en el fuerte de Penco había significado importantes bajas araucanas; y algunos héroes, como Tucapel y Talguén, habían sobrevivido tras huir y refugiarse en los bosques de Arauco.

Esta implícita comparatio entre la huida de Troya y la situación de los araucanos en su propia tierra se explicitaba en el canto XIII mediante la identificación de Talguén con Laocoonte y con Eneas, así como del fantasma de Lautaro con las figuras espectrales de Héctor y Creúsa. Con gran finura poética, Pedro de Oña hacía de ambos personajes nuevas versiones de héroes antiguos, figuras aglutinadoras, verdaderos caleidoscopios antárticos en los cuales se aunaban y reflejaban múltiples textos de la tradición. En su aemulatio, Pedro de Oña rescataba sobre todo la dimensión humana y patética del libro segundo de la Eneida, para enlazarlo con su modelo inmediato, $L a$ Araucana de Ercilla, de quien consolidaba y ampliaba los escasos fragmentos amorosos.

Mediante el repetido procedimiento de inversión, sin embargo, el poeta criollo privaba a sus personajes americanos del fin trágico que tenían las tramas antiguas imitadas. Con ello, Oña parecía no tanto rebajar a los héroes que él mismo había elevado al insertarlos en una prestigiosa cadena textual, sino destacar que el Arauco "aún no domado" seguía pendiente de ese término (generalmente trágico y doloroso) que, como explicó Victoria Pagán (2000), llevaba de las fuerzas caóticas de la batalla hacia la resolución de paz y la instalación de un nuevo orden

36 Virgilio, según Austin (p. xxiii), "translated the tradition into terms of human relationship that are more clearly comprehensible to the tormented world of the twentieth century than any time before". 
social y político por medio de la purificación de las secuelas de la guerra ${ }^{37}$. Sin el fin trágico de los episodios antiguos protagonizados por los araucanos, su energía pasional se diluía de la misma forma como se dilataba el conflicto que impedía la instalación del orden virreinal en el sur de Chile. En medio de una guerra sin fin, el criollo refugiaba a sus compatriotas araucanos en la humilde cabaña de Guemapu, hipotético espacio desde el cual anticiparía no sólo los futuros éxitos de García Hurtado de Mendoza, sino su propia integración. Ésta, en la pluma de Oña, se cumplía al menos en una dimensión netamente poética.

\section{REFERENCIAS}

Accatino, SANDra en prensa. "Laocoonte indiano. Fórmulas patéticas de la Antigüedad en Arauco domado de Pedro de Oña (1596)", Colonial Latin American Review.

Agustín, san 1992. Confessions. Ed. James J. O’Donnell, Clarendon Press, Oxford.

Austin, R.G. 1964. "Introduction" to P. Vergili Maronis Aeneidos Liber Secundus, Oxford University Press, Oxford, pp. ix-xxiii.

Blanco, Mercedes 2019. "Fábulas de amores en la épica de guerra. De la Araucana al Arauco domado", Bulletin Hispanique, 121, 1, pp. 17-54; doi: $10.4000 /$ bulletinhispanique.7589.

Bolzoni, Lina 2007. La estancia de la memoria. Modelos literarios e iconográficos en la época de la imprenta. Trads. Giovanna Gabriele y María de las Nieves Muñiz, Cátedra, Madrid.

Bolzoni, Lina 2012. Il lettore creativo. Percorsi cinquecenteschi fra memoria, gioco, scrittura, Guida Editori, Napoli.

Burrow, Colin 1997. "Virgils, from Dante to Milton", en The Cambridge Companion to Virgil. Ed. Charles Martindale, Cambridge University Press, Cambridge, pp. 79-90; doi: 10.1017/CCOL0521495393.

Carneiro, Sarissa en prensa. "Licencia para fingir: los límites de la ficción poética en el Virreinato del Perú. El proceso contra Arauco domado (Lima, 1596) de Pedro de Oña”, Revista de Crítica Literaria Latinoamericana.

Castillo Sandoval, Roberto 1995. “¿ ¿Una misma cosa con la vuestra»?: Ercilla, Pedro de Oña y la apropiación post-colonial de la patria

37 Cito a PAGÁn: "The aftermath of a battle stands between the chaotic forces of war and the resolution of peace; the battlefield lies between the pollution of war and the purification of funeral rites... Only through funeral rites is the natural process of death acculturated and brought into the human sphere; funeral rites civilize the violence of death on the battlefield and give it purpose... Once purified, the death and destruction of war can deliver the ideological message of the new social and political order" (pp. 446-447). 
araucana", Revista Iberoamericana, 170, pp. 231-247; doi: 10.5195/reviberoamer.1995.6406.

Castro Jiménez, María Dolores y Almudena Zapata Ferrer 2009. “Tópicos de cuño virgiliano en el Arauco domado de Pedro de Oña", en "Pectora mulcet". Estudios de retórica y oratoria latinas. Eds. Trinidad Arcos Pereira, Jorge Fernández López y Francisca Moya del Baño, Instituto de Estudios Riojanos, Logroño, t. 1, pp. 277-289.

Conte, Gian Biagio 2007. The poetry of pathos: Studies in Virgilian epic. Ed. S.J. Harrison, Oxford University Press, New York-Oxford.

Ercilla, Alonso de 2005 [1569, 1578 y 1589-1590]. La Araucana. Ed. Isaías Lerner, Cátedra, Madrid.

FernÁndez López, Jorge 2010-11. “«Ulises Telamonio» en América: retórica y mitología clásica en el Arauco domado de Pedro de Oña (1596)”, Faventia, 32/33, pp. 257-277.

Firbas, PAul 2017. "La poesía épica: entre la frontera y la ciudad", en Literatura y cultura en el Virreinato del Perú: apropiación y diferencia. Coords. Raquel Chang-Rodríguez y Carlos García-Bedoya, Pontificia Universidad Católica del Perú, Lima, pp. 139-174.

Galperin, Karina 2009. "The Dido episode in Ercilla's La Araucana and the critique of Empire”, Hispanic Review, 77, 1, pp. 31-67; doi: 10.1353/ hir.0.0046.

Gracián, Baltasar 2011 [1648]. Agudeza y arte de ingenio, en Obras completas. Ed. Santos Alonso, Cátedra, Madrid, pp. 431-742.

Homero 2011. Ilíada. Ed. y trad. Antonio López Eire, Cátedra, Madrid.

Kallendorf, Craig 2007. The other Virgil. Pessimistic readings of the "Aeneid" in Early Modern Culture, The Oxford University Press, New York.

Lida de Malkiel, María Rosa 1974. Dido en la literatura española: su retrato y defensa, Tamesis, London.

López Pinciano, Alonso 1596. Philosophía antigua poética, Thomas Iunti, Madrid.

Magli, Patrizia 1995. Il volto e l'anima. Fisiognomica e passioni, Bompiani, Milano.

Marrero-Fente, Raúl 2007. "Épica, fantasma y lamento: la retórica del duelo en La Araucana", Revista Iberoamericana, 73, 218, pp. 211-226; doi: 10.5195/reviberoamer.2007.5358.

Mazzotti, José Antonio 2008. "Paradojas de la épica criolla: Pedro de Oña entre la lealtad y el caos", en Épica y colonia. Ed. Paul Firbas, Universidad Mayor de San Marcos, Lima, pp. 231-261.

Mazzotti, José Antonio 2017. "Pedro de Oña y el criollismo poético", en Historia crítica de la literatura chilena. T. 1: La era colonial. Coord. Stefanie Massmann, LOM Ediciones, Santiago de Chile, pp. 101-114.

Oña, Pedro de 1596. Arauco domado, Antonio Ricardo Turín, Lima.

Oña, Pedro de 2014 [1596]. Arauco domado. Ed. Ornella Gianesin, Ibis, Pavia.

PagÁn, Victoria 2000. "The mourning after: Statius «Thebaid»12", The American Journal of Philology, 121, 3, pp. 423-452; doi: 10.1353/ ajp.2000.0042.

Pigman, G.W. 1980. "Versions of imitation in the Renaissance", Renaissance Quarterly, 33, 1, pp. 1-32; doi: 10.2307/2861533. 
Quint, DAvid 1993. Epic and empire: Politics and generic form from Virgil to Milton, Princeton University Press, Princeton.

Rodríguez, Mario 1981. "Un caso de imaginación colonizada: Arauco domado de Pedro de Oña”, Acta Literaria, 6, pp. 79-91.

Rodríguez, Mario 1984. "Estudio preliminar", en Diego Arias de Saavedra, Purén indómito. Ed. Mario Ferreccio, Biblioteca Nacional-Universidad de Concepción-Seminario de Filología Hispánica, Concepción, pp. 93-124.

Settis, Salvatore 1999. Laocoonte. Fama e stile, Donzelli Editore, Roma.

TAsso, Torquato 2014 [1581]. Gerusalemme liberata. Ed. Lanfranco Caretti, Einaudi, Torino.

Virgilio 2003. Obras completas. Trad. de Bucólicas, Geórgicas y Eneida de Aurelio Espinosa Pólit. Trad. de Apéndice virgiliano de Arturo Soler Ruiz. Ed. bilingüe, introd., apéndices y trad. de la Vida de Virgilio de Polluz Hernúñez, Cátedra, Madrid.

\section{APÉNDICE}

Tabla sintética de la imitación articulada en "Arauco domado", XIII

\begin{tabular}{|c|c|c|}
\hline $\begin{array}{l}\text { Libro II } \\
\text { de la "Eneida" }\end{array}$ & $\begin{array}{l}\text { Canto XIII de } \\
\text { "Arauco domado" }\end{array}$ & $\begin{array}{l}\text { Otros libros de la } \\
\text { "Eneida", "Geór- } \\
\text { gicas" de Virgilio e "La Araucana" } \\
\text { "Iliada" de Homero de Ercilla }\end{array}$ \\
\hline $\begin{array}{l}\text { Libro completo: } \\
\text { relato de Eneas a } \\
\text { Dido. }\end{array}$ & $\begin{array}{l}\rightarrow \text { Relatos indi- } \\
\text { rectos de Tuca- } \\
\text { pel y Gualeva } \\
\text { (acciones canto } \\
\text { V). } \\
\text { Relato de Tal- } \\
\text { guén a Tucapel y } \\
\text { Gualeva sobre lo } \\
\text { vivido tras huir } \\
\text { de la batalla. }\end{array}$ & \\
\hline
\end{tabular}

vv. 1-13: apertura.

vv. 13-49: caballo

inspeccionado.

vv. 40-56: Lao-

coonte.

vv. 57-194: Sinón;

v. 195-198: puen-

te.

vv. 199-231: Lao- $\rightarrow$ Octavas 34-43: $\leftarrow$ Cupido seduce $\leftarrow$ Guacolda se coonte.

Talguén y la ser- a Dido oculto piente: Laocoonte indiano. cuelga del cuello de Lautaro. 


\section{APÉNDICE}

Tabla sintética de la imitación articulada (continúa)

\begin{tabular}{|c|c|c|c|}
\hline $\begin{array}{l}\text { Libro II } \\
\text { de la "Eneida" }\end{array}$ & $\begin{array}{l}\text { Canto XIII de } \\
\text { "Arauco domado" }\end{array}$ & $\begin{array}{l}\text { Otros libros de la } \\
\text { "Eneida", "Geór- } \\
\text { gicas" de Virgilio e } \\
\text { "Iliada" de Homero }\end{array}$ & $\begin{array}{l}\text { "La Araucana" } \\
\text { de Ercilla }\end{array}$ \\
\hline \multicolumn{4}{|l|}{$\begin{array}{l}\text { vv. 232-249: caba- } \\
\text { llo admitido. }\end{array}$} \\
\hline $\begin{array}{l}\text { vv. 250-297: } \\
\text { griegos entran } \\
\text { a Troya; Eneas y } \\
\text { Héctor. }\end{array}$ & $\begin{array}{l}\rightarrow \text { 44-91: apari- } \\
\text { ción espectral de } \\
\text { Lautaro } \\
\text { Anotaciones al } \\
\text { margen: OcTAVA } \\
\text { 52: *Imitación } \\
\text { de Virgilio, } 2 \text { de } \\
\text { la Eneida. } \\
\text { OcTAVA 64: } \\
\text { *Virgilio, } 2 \text { de la } \\
\text { Eneida. }\end{array}$ & $\begin{array}{l}\leftarrow \text { Espectro de } \\
\text { Siqueo; aparece a } \\
\text { Dido para contar } \\
\text { verdadera causa } \\
\text { de su muerte } \\
\text { (Eneida, I, vv. 353- } \\
356) . \\
\leftarrow \text { Espectro de } \\
\text { Patroclo; pide } \\
\text { ritos fúnebres a } \\
\text { Aquiles (Iliada). }\end{array}$ & $\begin{array}{l}\leftarrow \text { Diálogo entre } \\
\text { Guacolda y Lau- } \\
\text { taro antes de su } \\
\text { muerte (La Arau- } \\
\text { cana, 13). }\end{array}$ \\
\hline
\end{tabular}

vv. 298-452: resistencia de Eneas, con camino al fracaso desde v. 402.

vv. 453-468: Eneas en el palacio.

vv. 469-505: entrada de Pirro.

vv. 506-553: muer- $\rightarrow$ Octavas 30-32:

te de Polites y de recuerdo de Qui-

Príamo; clímax dora lleva a Taldel libro. guén a huir de

Eneas recuerda la batalla en el a los suyos al ver fuerte de Penco. la muerte de Príamo.

vv. 559-566: proemio a segunda parte del libro.

vv. 567-588: interpolación. 
APÉNDICE

Tabla sintética de la imitación articulada (concluye)

\begin{tabular}{|c|c|c|}
\hline $\begin{array}{l}\text { Libro II } \\
\text { de la "Eneida" }\end{array}$ & $\begin{array}{l}\text { Canto XIII de } \\
\text { "Arauco domado" }\end{array}$ & $\begin{array}{l}\text { Otros libros de la } \\
\text { "Eneida", "Geór- } \\
\text { gicas" de Virgilio e "La Araucana" } \\
\text { "Ilíada" de Homero de Ercilla }\end{array}$ \\
\hline \multicolumn{3}{|l|}{$\begin{array}{l}\text { vv. 589-633: Venus } \\
\text { y Eneas. }\end{array}$} \\
\hline $\begin{array}{l}\text { vv. 634-704: cam- } \\
\text { bio de Anquises. }\end{array}$ & $\begin{array}{l}\rightarrow \text { Aparición de } \\
\text { serpiente como } \\
\text { buen agüero. }\end{array}$ & \\
\hline $\begin{array}{l}\text { vv. 705-795: parti- } \\
\text { da de Eneas y los } \\
\text { suyos; } \\
\text { pérdida de Creú- } \\
\text { sa. }\end{array}$ & $\begin{array}{l}\rightarrow \text { Tucapel viste } \\
\text { piel de la leona } \\
\text { para el camino. } \\
\rightarrow \text { Abrazo fallido } \\
\text { de Talguén a } \\
\text { Lautaro. }\end{array}$ & \\
\hline vv. 796-804: coda. & $\begin{array}{l}\text { Coda pastoril: } \\
\text { cabaña de Gue- } \\
\text { mapu. }\end{array}$ & $\leftarrow$ Geórgicas, IV. \\
\hline
\end{tabular}


